\title{
CONVENTIONAL AND MOLECULAR DETECTION OF MYCOBACTERIUM BOVIS IN ABURDEN ANGUS CATTLE AND HUMAN CONTACT IN THE NEW VALLEY GOVERNORATE, EGYPT
}

\author{
YASSER F. ELNAKER ${ }^{1}$; NAGWA T. ELSHARAWY ${ }^{2}$; MOHAMED S. DAIB ${ }^{3}$; \\ ATTIA A. ELGEDAWY ${ }^{4}$ and NERMIN A.IBRAHIM ${ }^{5}$ \\ ${ }^{1}$ Infectious Diseases, Animal Medicine Department, Fac. Vet. Med., New Valley, Assiut Univ, Egypt. \\ ${ }^{2}$ Dept. of Food Hygiene Fac. Vet. Med., New Valley, Assiut Univ, Egypt. \\ ${ }^{3}$ Department of Animal Hygiene and Zoonoses, Fac. Vet. Med., New Valley, Assiut Univ, Egypt. \\ ${ }^{4}$ TB Unit, Animal Health Research Institute, Dokki, Egypt. \\ ${ }^{5}$ Bacteriology, Mycology and Immunology Department, Faculty of Veterinary \\ Medicine, Mansoura University, Egypt.
}

Received: 8 March 2018; Accepted: 30 April 2018

\begin{abstract}
In this work, Mycobacterium bovis isolated and identified by microbiological culture and RT-PCR from emergency slaughtered aburden Angus cattle suffering from chronic mastitis and respiratory manifestations in private farm not perform tuberculin test in New Valley governorate, Egypt. Furthermore, other contact cattle, sheep and human in the farm examined by ELISA, found that $22.2 \%$ (4/18) cattle in the farm were positive, with complete absence of infection in the sheep and contact persons in the farm. The high percent of $M$. bovis was detected by RT-PCR $(83.33 \%)$ followed by microbiological culture $(72.22 \%)$ in slaughtered cattle. The highest percent of tubercles lesion observed in thoracic cavity followed by the lung then the udder. From our study we can concluded that, $M$. bovis isolated and identified from imported Aburden Angus cow in New Valley Governorate. Also, ELISA test need further evaluation before using as an exploratory test for diagnosis of BTB in animal and human.
\end{abstract}

Key words: Post mortem inspection, bovine tuberculosis, RT-PCR, ELISA.

\section{INTRODUCTION}

Tuberculosis (TB) considers one of the greatest dangerous chronic, zoonotic infectious diseases, which risking consumers' health and almost species of animal causing socioeconomic implications due to reduction of productivity of tuberculous animal and condemnation of slaughtered carcasses (Sa'idu et al., 2015). Bovine TB (BTB) is caused by Mycobacterium bovis (M. bovis), aerobic bacterium, needs long period for growth and it is related to mycobacterium tuberculosis complex, itcausing intercellular infection, which, result in a chronic disease in animal. In addition to that it infects humans through inhalation, ingestion, and by contact with mucous membranes and broken skin (Bilal et al., 2010; Elsify et al., 2013). The name of TB comes from "tubercle" which affect lymph nodes (LNs); it remains for months or years to appear. However, TB

Corresponding author: Dr. YASSER F. ELNAKER

E-mail address: yasserelnaker@yahoo.com

Present address: Infectious Diseases, Animal Medicine Department, Fac. Vet. Med., New Valley, Assiut Univ, Egypt. may be latent without causing any signs, it also causing general illness from; fluctuating fever, diarrhea, weakness, loss of appetite, loss weight, protruding LNs until death of diseased animal and man, which maybe delay for many years after the infection (Nalapa et al., 2017).

BTB is serious zoonotic disease chiefly in developing countries where it is endemic there (Pandey et al., 2013). In Egypt, there are no official reports about the spreading map of TB infection (OIE, 2009).

BTB is detected either through skin testing (single cervical tuberculin) testing of cattle through surveillance program (covers the individual cattle of small holders) or in abattoir through observing LNs and lungs tubercles in post slaughter inspection then, confirmed by microscopic detection of acid fast bacilli or by growth on selective media. So perfect meat inspections reduce the chance of introducing BTB into food chain, allows the veterinary official team to trace the infected animal herd origin to test them and to eliminate infected animals. Treatment of infected animals are expensive and need long period 
to eliminate the disease (Neill et al., 2005; Abdellrazeq et al., 2016; Gizaw et al., 2017).

PCR assays can be used for easily identification of mycobacterium. Amplification of the Mycobacterium DNA by PCR has sensitivity equal or greater than that of the culture method consequently, it is more reliable technique for rapid diagnosis (Ramadan et al., 2012).

Enzyme Linked Immunosorbant Assay (ELISA) from the important serological diagnostic tests used for BTB detection. It is a sensitive method for antibodies measurement in the sera of tuberculous animals (Elsify et al., 2013).

This work aimed to diagnosis and molecular identification of $M$. bovis in emergency slaughtered cow and examination of all animals as well as farm workers with available ELISA test, in a private farm in Elkharga city, New Valley governorate.

\section{MATERIALS AND METHODS}

Animals: Study were conducted in private farm containing 19 imported A burden Angus cattle, 18 native breed sheep and 10 human contacts in Elkharga city, the capital of New Valley Governorate. It is a part of the oasis, which is located to the west of the Nile Valley. Wherein one cow emergency slaughtered with a history of chronic mastitis and pneumonia that not respond to treatment. There no history about tuberculin test examination. The data of the animals and farm workers in the farm were recorded.

\section{Post slaughter examination.}

Postmortem inspection for the presence of tubercles according to Torell et al. (2003).

\section{Tubercles samples.}

18 tuberculous LNs were collected, identified and preserved at $-20^{\circ} \mathrm{C}$ till transported on icebox to the TB unit in Animals Health Researches Institute, ELDokki, Egypt, for Mycobacterium isolation and identification.

\section{- Blood samples.}

46blood samples were obtained from 18 cattle, 18 sheep and 10 farm workers without anticoagulant for serum separation for ELISA test, which performed in TB unit in Animals Health Researches Institute, ELDokki, Egypt.

\section{- Culture of Mycobacterium,}

Isolation of Mycobacterium spp. on selective media according to Marks technique (Ratledge and Stanford, 1982) as follow:
Suspected tissues were cut into small pieces and mixed with $2 \mathrm{ml}$ sterile distilled water, ground in the grinder until suspension was obtained. Two $\mathrm{ml}$ of $4 \%$ $\mathrm{H}_{2} \mathrm{SO}_{4}$ were added to the mixture then incubated at $37{ }^{\circ} \mathrm{C} / 30$ minutes. The mixture was diluted with 16 $\mathrm{ml}$ of sterile distilled water and centrifuged at 3000 $\mathrm{rpm} / 20$ minutes, the supernatant fluid was poured off into disinfectant (5\% phenol solution) and the obtained sediment was re-suspended in $0.5 \mathrm{ml}$ sterile distilled water. Using sterile plastic Pasteur pipette, some of the suspended deposit were inoculated onto two Lowenstein-Jensen slants (one tube with glycerol and the other with pyruvate for each sample) and Middle brook 7 H10, 7 H 11 agar media. Then all tubes were incubated at micro aerophilic condition at $37{ }^{\circ} \mathrm{C}$ and examined daily during the first week and then every week for at least two months. The media checked weekly for growth of acid-fastbacilli, and identified microscopically by Ziehl-Neelsen (ZN) stain according to (Robbe-Austerman et al., 2013).

\section{Real time PCR used for detection of M.bovis.}

- $(\boldsymbol{R T}$-PCR) kit (biovision).

DNA extraction: Each piece of infected tissue was homogenized in PBS $(0.14 \mathrm{M} \mathrm{NaCl}, 4 \mathrm{mM} \mathrm{KCl}, 8 \mathrm{mM}$ Na2HPO4, 2mM KH2PO4, pH 6.5 buffer) according to Wards et al. (1995). Isolation of mycobacterial DNA from infected tissues: The extraction carried out according to instruction of extraction kit (Sigma).

Detection of $M$. boviscomplex: Using kits obtained from biovision ${ }^{\circledR}$. Real-time PCR was performed according to Michel et al. (2011)using MTplexdtecRT-qPCR Test (Edifici-Quórum3, Spain) that comprises a series of species - specific targeted reagents designed for detection of all species contained in the Mycobacterium bovis complex by the following reagents: $0.375 \mathrm{nM}$ of each primer (Mbovis.88.F: 5'CGC CTT CCT AACCAG AAT TG3'and Mbovis.88.R: 5' GGA GAG CGC CGT TGTAGG-3'), 10 $\mu \mathrm{L}$ of Fast Eva Greenq PCR Master Mix (Biotium, USA) in a $20 \mu \mathrm{L}$ reaction. Thermocyler (QuantStudio7, Life Technologies, USA) programme was as follows: $95^{\circ} \mathrm{C} / 5 \mathrm{~min}$, followed by 35 cycles at $95^{\circ} \mathrm{C} / 15 \mathrm{sac}, 63^{\circ} \mathrm{C} / 20 \mathrm{sac}$, and $72^{\circ} \mathrm{C} / 30 \mathrm{sac}$, with the reading cycle length. The curve denaturation were at $72-99^{\circ} \mathrm{C}$, with intervals of fluorescence at every $1 \%$ rise in temperature (Sales et al., 2014). The reaction was run in Applied Biosystem Step One TM Real Time PCR System, FAM fluorogenic signal was collected, and the cycle threshold of the reactions was detected by Step One ${ }^{\mathrm{TM}}$ software version 2.2.2 (Life Technology). The threshold cycle (CT) defined as 10 times the standard deviation of the mean baseline fluorescence emission calculated for PCR cycles 3-15. For a sample to be considered positive, the corresponding amplification curve had to exhibit three distinct phases (geometric, 
linear, and plateau) that characterize the progression of the PCR reaction.

\section{- ELISA test}

Detection of $M$. bovis in serum samples of contact animals and farm workers of infected cow using ELISA as following; Serum samples were observed by Bovine Tuberculosis Antibody ELISA kit, Wuhan Unibiotest Co., Ltd, is an indirect ELISA Assay for the qualitative detection of M.bovis antibody in serum. Additionally the Ag was comptable with sheep and human serum samples. The test were performed according to manufacture's instruction.

\section{RESULTS}

Postmortem Inspection: TB characteristic lesions are well known as granulomas most commonly noted in the lungs and LNs. Our postmortem inspection declared infigures (1\&2). Figure (1) from $(A-E)$ declared TB lesions in LNs as yellowish caseation and calcification of mesenteric, precular, presacupular, supramammary and bronchial, LNs. Figure (2) from $(\mathrm{F}-\mathrm{H})$ revealed the TB lesions in udder, intercostal LNs and lung tissues respectively.
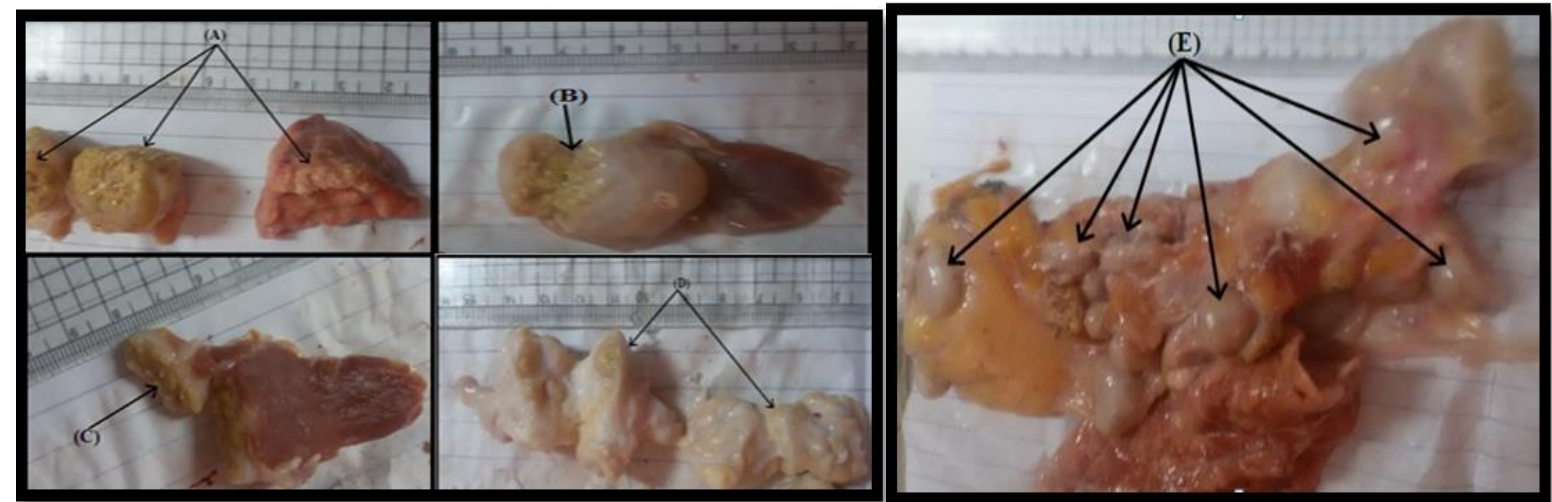

Figure (1): Declaration of TB Detected Lesions in Different LNs

Gross lesions of LNs sampling tissues, most LNs were in advanced stage of tuberculosis. (A, B, C) declared yellowish caseation and calcification different LNs. Inprescapular \& precular LNs. (D) viewed the casiation and calcification on the supramammary LNs (E) observed the tubercles in bronchial LNs.

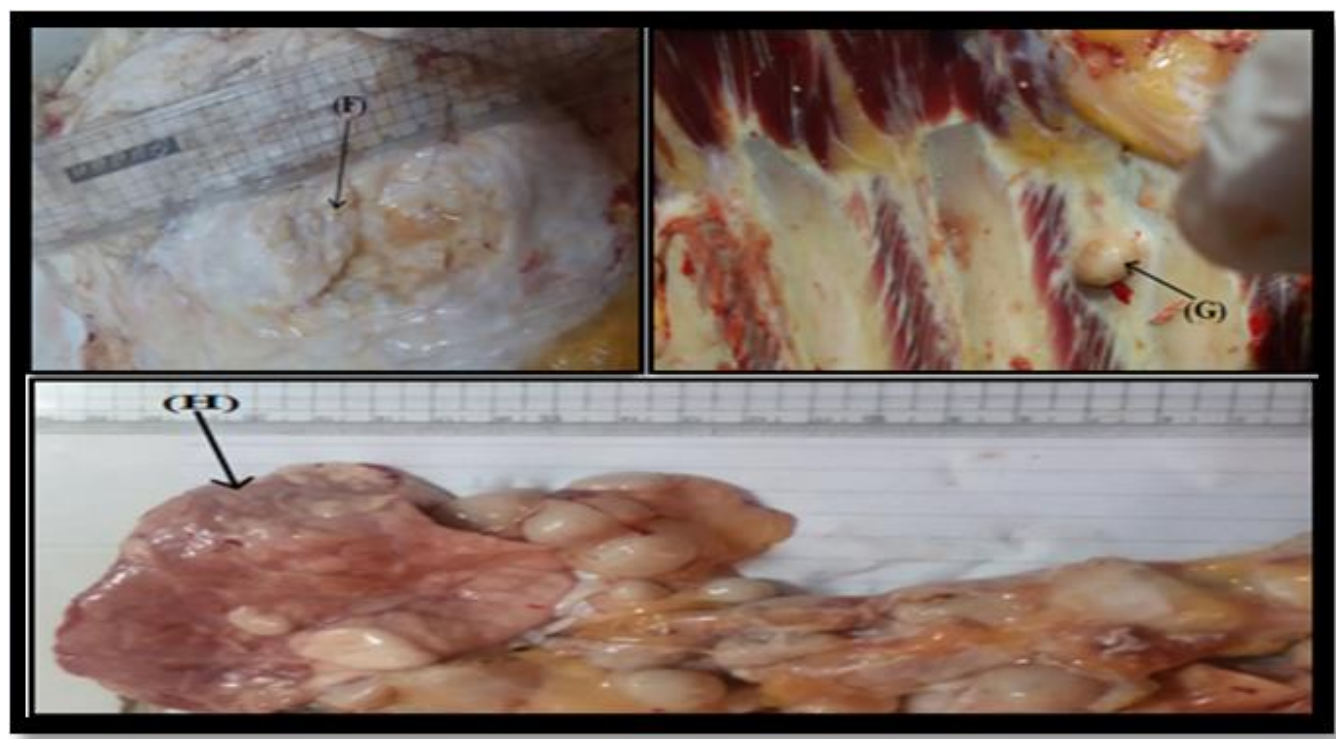

Figure (2): Declaration of TB Detected Lesions in Different Organs

Gross lesions of TB infected organs, which were in advanced stage of tuberculosis. (F) Represented the infected TB udder, which were mainly calcified and granulated. (G) The tubercle lesion appear between ribs and intercostal muscle with yellowish of adipose tissues that indicate the severity and advancement of the infection stage. $(\mathrm{H})$ Lung tissue has bale coloration with large numerous tubercles. 


\section{Real time PCR}

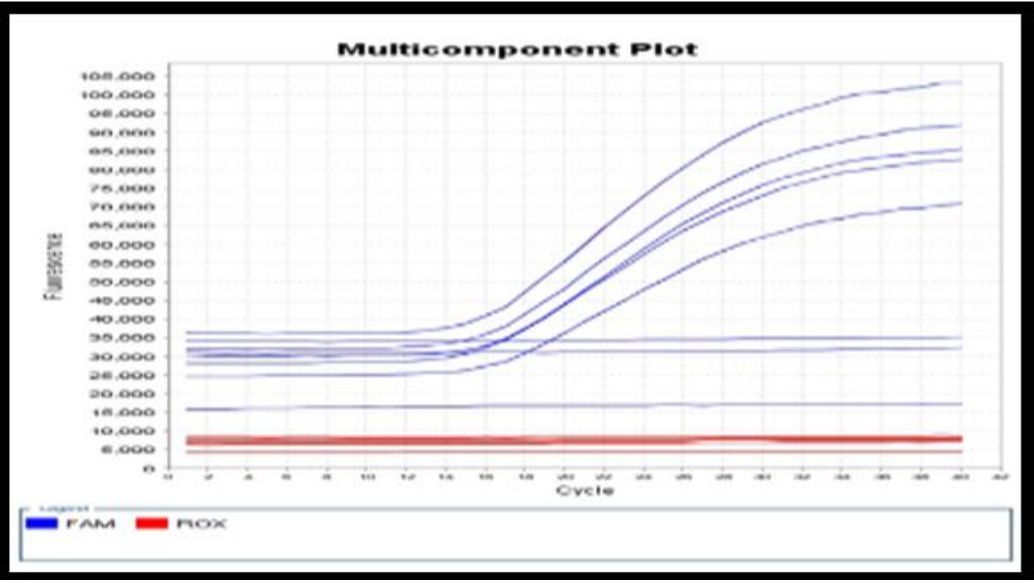

Figure (3): The amplification blot of tuberculosis samples.

Results: Figure (3) illustrated the amplification blot of tubercles samples, Analysis for the amplification blot in its linear form declared that the photo consisted of 4 positive examined tubercles samples at cycle 12 and one control positive sample and three negative samples.

Analysis for the amplification blot in its linear form:
1- This photo consisted of four positive samples at cycle 12 and one control positive sample.

2- There are three negative samples.

3 - The used reference dye is (FAM).

4- The run is for 45 cycles.

Microbial culture: From 18 tubercles, lesions examined by culture isolated colonies were identified by morphology and staining by $\mathrm{ZN}$ stain. only 15 lesions were positive.

Table 1: Correlation between different tests in diagnosis of mycobacterium in 18 lesions from the emergency slaughtered a burden Angus carcass.

\begin{tabular}{cccc}
\hline Lesion & Total lesion & Positive & Negative \\
\hline Inspection & 18 & $18(100 \%)$ & $0(0 \%)$ \\
\hline Microbiological culture & 18 & $13(72.22)$ & $5(27.78 \%)$ \\
\hline RT-PCR & 18 & $15(83.33)$ & $3(16.67 \%)$ \\
\hline
\end{tabular}

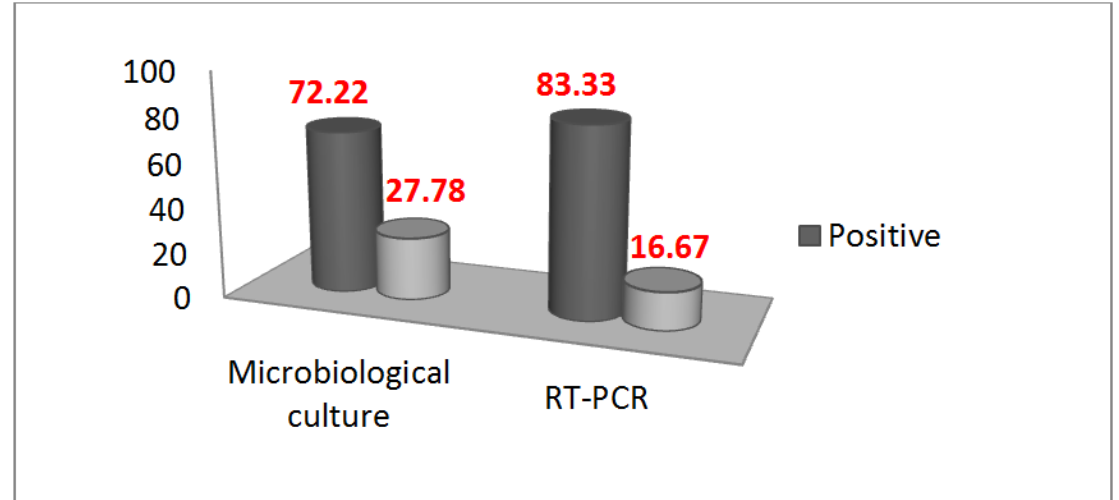

Figure 4: Correlation between different tests in diagnosis of mycobacterium in lesions obtained from the emergency slaughtered aburden Angus carcass.

In Figure (4) showed comparison between diagnosis of BTB by different tests, the RT-PCR is highly sensitive to diagnose BTB in lesions followed by mycobacterium culture by $83.33 \%$ and $72.22 \%$ respectively.

Prevalence of mycobacterium in contact cattle, sheep and human
In which serum samples from 18 cattle, 18 sheep and 10 farm workers examined by ELISA, revealed that (figure 5) the prevalence of BTB were four positive for mycobacterium in serum samples of examined cows (4/18) by $22.2 \%$. On other hand, there are no positive serum samples for sheep and human, which meaning that all contact persons and sheep were free from BTB infection. (Table 2) (Figure 5) 
Table 2: Prevalence of M.bovis in cow, sheep and contact human in private farm using ELISA.

\begin{tabular}{cccc}
\hline Species & Total examined & Positive by ELISA & $\%$ \\
\hline Cattle & 18 & 4 & 22.22 \\
\hline Sheep & 18 & 0 & 0 \\
\hline Human & 10 & 0 & 0 \\
\hline
\end{tabular}

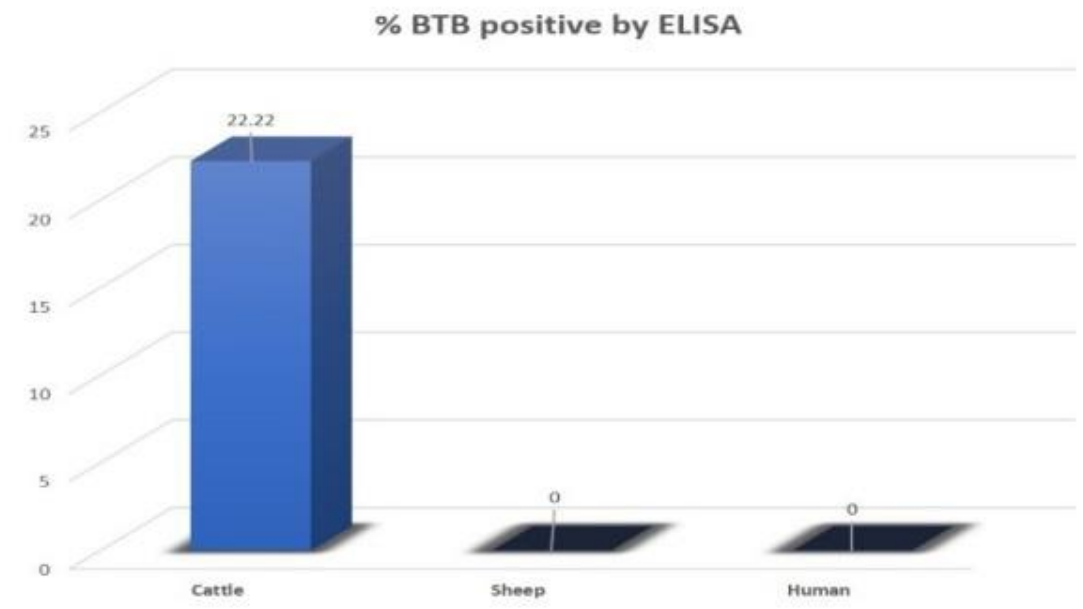

Figure (5): Prevalence of TB in serum of cow and sheep using ELISA.

\section{DISCUSSION}

The main cause which making animalsownerdo not slaughter the suspected animal inside the abattoir is to avoid the quarantine and the other notifiable procedures, so there is no any positive BTB cases report in all Elkharga abattoirs and that is why we detect the positive BTB case accidentally in carcass slaughtered outside the abattoir.

Diagnosis of BTB could be divided mainly into two categories; direct assays (convetional test and PCR) that generally rely on detection of the organism within samples collected at necropsy and indirect assays (detection of cellular or humoral immune response (Mackintosh et al., 2007; Wadhwa et al., 2012). Post slaughter inspection results were illustrated and revealed that most LNs were with high suspicious with tuberculosis for this reason rigorous meat inspections are an important procedure for eradication or constantdecline of zoonotic BTB (Good, 2006; Pavlik, 2006). The obtained results which study the prevalence of BTB in different LNs and carcass organs reported that the highest incidence of BTB by different diagnostic technique recorded $(100 \%)$ in udder, supramammary LN., followed by lung, bronchial LNs., mesenteric LNs, prescapular LNs. and intercostal LNs. Nearly similar results mentioned by Teklu et al. (2004) who found about $83.7 \%$ of BTB lesions in the thoracic LNs, followed by $11.6 \%$ in mesenteric LNs. Similar results also reported by Elias et al. (2008) in Ethiopia and by
Oloya et al. (2007) in Uganda, while lower results observed by Gizaw et al. (2017) who detected the proportions of BTB lesions in the bronchial $27.9 \%$ and $11.6 \%$ in mesenteric LNs. The high incidence of BTB in organs depend on the rout of infection (respiration or ingestion).

In confirmation of the infection using microbiological culture and RT-PCR that showed amplification blot in its linear form declared that the photo consisted of 4 positive samples examined tubercles samples at cycle 12 and one control positive sample and three negative samples.

PCR techniques is very important tool for diagnosis and typing of BTB (Mirza et al., 2003). This study comparing between RT-PCR and microbiological culture, the results declared that the detection potency of RT-PCR $(83.3 \%)$ were higher than microbiological culture $(72.2 \%)$. Similar results obtained by Abdul Basit et al. (2015) and Rocha et al. (2017) who found that microbiological culture was the least efficiency in detection of BTB while RT-PCR was the most accurate one.

ELISA test were used for serological examination of all animals and human in this farm; the results were Illustrated showed that $22.2 \%$ of cows were mycobacterium positive (4/18). On other hand, sheep and human samples were negative. Nearly similar results were obtained by Al-Fattli (2016) who reported that the overall seroprevalence in cattle was 
$20.16 \%$ using ELISA. However, higer results were observed by Asiak et al. (2007) who concluded that $36.3 \%$ of cattle were TB positive by ELISA and $43.5 \%$ by (Hassanain et al., 2009). On the other hand Lower results were established by Koni et al. (2015) (1.4\%) and Wambua (2015) (3.57\%).

Diagnosis of extra-pulmonary BTB is difficult in its early stages, due to nonspecific clinical features (Arikan et al., 1998). ELISA on human sera has excellent sensitivity and specificity that help in early diagnosis of BTB as well as detection of several extrapulmonary cases such as genitourinary TB, miliary TB and ocular TB (Levy et al., 1988; Ahmad et al., 1995; Upadhye et al., 2007). In this study, human samples revealed complete absence of any positive TB case by ELISA.

Higher results were reported by Chen et al. (2009) who reporteda prevalence of $M$. bovis were $(0.34 \%)$ among human, Aliyu et al. (2013) (0.3\%) and (Firdessa et al., 2013) (0.4\%). Moreover, TorresGonzalez et al. (2013) detected high prevalence of latent and pulmonary TB among workers occupationally exposed to cattle infected with $M$. bovis in non-ventilated spaces. This explain our result as this farm was open farm with good ventilation or my be due to short period of contact with the imported infected breed.

Animal breed also play a role in different susceptibility to the TB infection which leading to appearance of infection in specific sensitive breed while other breed in the same farm may not take TB infection (Vordermeier et al., 2012). Moreovere, ELISA could be a useful complementary test with tubercline test in detecting anergic tuberculous animals (subclinical infection) that represent a risk for the rest of the herd.

\section{CONCLUSIONS}

In this study we diagnosed $M$. bovis in an emergency slaughtered cow by postmortem inspection, mycobacterium culture and RT-PCR, besides ELISA that performed to detect infection in other four cases from contact animals, so we can concluded that, ELISA is an assistant in BTB diagnosis specially with absence of tubercline test. Increasing public a wareness on the BTB transmission methods.

\section{ACKNOWLEDGEMENTS}

The authors gratefully thank the farm owner for their help in the examination of the slaughtered animals and providing the samples under the study.

\section{COMPETING INTERESTS}

All authors are certifying that there is no conflict of interest regarding the publication of this paper.

\section{REFERENCES}

Abdellrazeq, G.S.; Elnaggar, M.M.; Osman, H.S.; Davis, W.C. and Singh, M. (2016): Prevalence of Bovine Tuberculosis in Egyptian Cattle and the Standardization of the Interferon-gamma Assay as an Ancillary Test Transboundary and emerging diseases. 63: 497-507.

Abdul Basit; Hussain, M.; Ayaz, S.; Shahid, M.; Rahim, K.; Ahmad, I.; Ullah, R.; Hashem, A.; AbdAllah, E. and Alqarawi, A.A. (2015): Isolation and identification of Mycobacterium bovis and Mycobacterium tuberculosis from animal tissues by conventional and molecular method Indian J. Anim. Res. 49: 687-693.

Ahmad, A.; Afghan, S.; Raykundalia, C. and Catty, D. (1995): Diagnosis of tuberculosis by using ELISA to detect $38 \mathrm{kDa}$ Mycobacterial Antigen in the patients JIAS. 8: 155-160.

Al-Fattli, H.H.H. (2016): The clinical and serological diagnosis of Mycobacterium bovis in blood and milk serums of lactating cows by IDEXX ELISA test in Wasit and Dhi-Qar provinces/ Iraq Journal of Contemporary Medical Sciences. 2: 70-73.

Aliyu, G.; El-Kamary, S.S.; Abimiku, A.L.; Ezati, N.; Mosunmola, I.; Hungerford, L.; Brown, C.; Tracy, K.J.; Obasanya, J. and Blattner, W. (2013): Mycobacterial Etiology of Pulmonary Tuberculosis and Association with HIV Infection and Multidrug Resistance in Northern Nigeria Tuberculosis Research and Treatment. 2013: 650561.

Arikan, S.; Tuncer, S.; Us, D.; Ünal, S. and Ustacelebi, S. (1998): Anti-Kp 90 IgA antibodies in the diagnosis of active tuberculosis Chest. 114: 1253-1257.

Asiak, I.; Ohore, O.; Emikpe, B.; Abatan, O. and Ockiya, M. (2007): The use of ELISA in the detection of bovine tuberculosis in slaughtered trade cattle and sedentary herds in South West Nigeria J. Anim. Vet. Adv. 6: 883-886.

Bilal, S.; Iqbal, M.; Murphy, P. and Power, J. (2010): Human bovine tuberculosis-remains in the differential Journal of medical microbiology. 59: 1379-1382.

Chen, Y.; Chao, Y.; Deng, Q.; Liu, T.; Xiang, J.; Chen, J.; Zhou, J.; Zhan, Z.; Kuang, Y. and Cai, H. (2009): Potential challenges to the Stop TB Plan for humans in China; cattle maintain M. bovis and M. tuberculosis Tuberculosis. 89: 95-100.

Elias, K.; Hussein, D.; Asseged, B.; Wondwossen, T. and Gebeyehu, M. (2008): Status of bovine tuberculosis in Addis Ababa dairy farms Revue scientifique et technique. 27: 915.

Elsify, A.; Nayel, M.; Hazem, S.; Tarabess, R.; Akram S.A.M. and Hassan H.A.E.G.M. (2013): Sero- 
diagnosis of bovine tuberculosis by ELISA using bovine PPD and ST. CF BS. VET. MED. J.7TH SCl. CONF. 22: 126-129.

Firdessa, R.; Berg, S.; Hailu, E.; Schelling, E.; Gumi, B.; Erenso, G.; Gadisa, E.; Kiros, T.; Habtamu, M. and Hussein, J. (2013): Mycobacterial lineages causing pulmonary and extrapulmonary tuberculosis, Ethiopia Emerging infectious diseases. 19: 460.

Gizaw, T.T.; Minalu, B.A. and Asfaw, Y.T. (2017): Prevalence of Bovine Tuberculosis Using Abattoir Meat Inspection in Cattle Slaughtered at Gondar Elfora Abattoir, North Ethiopia Animal and Veterinary Sciences. 5: 89.

Good, M. (2006): Bovine tuberculosis eradication in Ireland Irish Veterinary Journal. 59: 154.

Hassanain, N.A.; Hassanain, M.A.; Soliman, Y.; Ghazy, A.A. and Ghazyi, Y.A. (2009): Bovine tuberculosis in a dairy cattle farm as a threat to public health African Journal of Microbiology Research. 3: 446-450.

Koni, A.; Juma, A.; Morini, M.; Nardelli, S.; Connor, $R$. and Koleci, X. (2015): Assessment of an ELISA method to support surveillance of bovine tuberculosis in Albania Irish veterinary journal. 69: 11.

Levy, H.; Wadee, A.A.; Feldman, C. and Rabson, A.R. (1988): Enzyme-linked immunosorbent assay for the detection of antibodies against Mycobacterium tuberculosis in bronchial washings and serum Chest. 93: 762-766.

Mackintosh, C.; Littlejohn, R. and Thompson, B. (2007): Improving the tuberculin test in red deer (Cervus elaphus) DEER BRANCH COURSE. 24: 83.

Michel, A.; Cooper, D.; Jooste, J.; De Klerk, L.-M. and Jolles, A. (2011): Approaches towards optimising the gamma interferon assay for diagnosing Mycobacterium bovis infection in African buffalo (Syncerus caffer) Preventive veterinary medicine. 98: 142-151.

Mirza, S.; Restrepo, B.I.; Mccormick, J.B. and FisherHoch, S.P. (2003): Diagnosis of tuberculosis lymphadenitis using a polymerase chain reaction on peripheral blood mononuclear cells The American journal of tropical medicine and hygiene. 69: 461-465.

Nalapa, D.P.; Muwonge, A.; Kankya, C. and OleaPopelka, F. (2017): Prevalence of tuberculous lesion in cattle slaughtered in Mubende district, Uganda BMC veterinary research. 13: 73.

Neill, S.; Skuce, R. and Pollock, J. (2005): Tuberculosis-new light from an old window Journal of applied microbiology. 98: 12611269.
Oie (2009): Office International des Epizooties (OIE) Terrestrial manual: Bovine Tuberculosis, World Health Organization for Animal Health.

Oloya, J.; Kazwala, R.; Lund, A.; Opuda-Asibo, J.; Demelash, B.; Skjerve, E.; Johansen, T. and Djønne, B. (2007): Characterisation of mycobacteria isolated from slaughter cattle in pastoral regions of Uganda BMC microbiology. 7: 95

Pandey, G.S.; Hang'ombe, B.M.; Mushabati, F. and Kataba, A. (2013): Prevalence of tuberculosis among southern Zambian cattle and isolation of Mycobacterium bovis in raw milk obtained from tuberculin positive cows Veterinary World. 6: 986-991.

Pavlik, I. (2006): Control and eradication of bovine tuberculosis in central Europe Mycobacterium bovis infection in animals and humans. 136148.

Ramadan, H.H.; El-Gohary, A.H.; Mohamed, A.A. and Nasr, E.A. (2012): Detection of Mycobacterium bovis and Mycobacterium tuberculosis from clinical samples by conventional and molecular techniques in Egypt Global Veterinaria. 9: 648-654.

Ratledge, C. and Stanford, J. (1982): The biology of the mycobacteria.

Robbe-Austerman, S.; Bravo, D.M. and Harris, B. (2013): Comparison of the MGIT 960, BACTEC 460 TB and solid media for isolation of Mycobacterium bovis in United States veterinary specimens BMC veterinary research. 9: 74.

Rocha, V.C.F.; Figueiredo, S.C.D.; Rosales, C.A.R.; Porto, C.D.; Sequeira, J.L.; Ferreira Neto, J.S.; Paes, A.C. and Salgado, V.R. (2017): Infection by Mycobacterium bovis in a dog from Brazil brazilian journal of microbiology. 48: 109-112.

Sa'idu, A.S.; Okolocha, E.C.; Dzikwi, A.A.; Gamawa, A.A.; Ibrahim, S.; Kwaga, J.K.P.; Usman, A. and Maigari, S.A. (2015): Public Health Implications and Risk Factors Assessment of Mycobacterium bovis Infections among Abattoir Personnel in Bauchi State, Nigeria Journal of Veterinary Medicine. 2015: 718193.

Sales, M.; Fonseca Jr, A.; Orzil, L.; Alencar, A.; Hodon, M.; Issa, M.; Soares Filho, P.; Silva, M.; Lage, A. and Heinemann, M. (2014): Validation of two real-time PCRs targeting the PE-PGRS 20 gene and the region of difference 4 for the characterization of Mycobacterium bovis isolates Genet Mol Res. 13: 4607-4616.

Teklu, A.; Asseged, B.; Yimer, E.; Gebeyehu, M. and Woldesenbet, Z. (2004): Tuberculous lesions not detected by routine abattoir inspection: the experience of the Hossana municipal abattoir, southern Ethiopia Revue Scientifique 
et Technique-Office International Des Epizooties. 23: 957-964.

Torell, R.; Bruce, B.; Kvasnicka, B. and Conley, K. (2003): Methods of Determining Age of Cattle. The University of Nevada Cattle Producer's Library-CL. 712.

Torres-Gonzalez, P.; Soberanis-Ramos, O.; MartinezGamboa, A.; Chavez-Mazari, B.; BarriosHerrera, M. T.; Torres-Rojas, M.; Cruz-Hervert, L.P.; Garcia-Garcia, L.; Singh, M. and Gonzalez-Aguirre, A. (2013): Prevalence of latent and active tuberculosis among dairy farm workers exposed to cattle infected by Mycobacterium bovis PLoS neglected tropical diseases. 7: e2177.

Upadhye, V.; Shende, N.; Kumar, S. and Harinath, $B$. (2007): Detection of antibody and antigen in extrapulmonary tuberculosis patients' sera using a cocktail of mycobacterial excretory secretory antigens and their antibodies Biomedical Research. 18.
Vordermeier, M.; Ameni, G.; Berg, S.; Bishop, R.; Robertson, B.D.; Aseffa, A.; Hewinson, R.G. and Young, D.B. (2012): The influence of cattle breed on susceptibility to bovine tuberculosis in Ethiopia Comparative Immunology, Microbiology and Infectious Diseases. 35: 227-232.

Wadhwa, A.; Hickling, G.J. and Eda, S. (2012): Opportunities for improved serodiagnosis of human tuberculosis, bovine tuberculosis, and paratuberculosis Veterinary medicine international. 2012.

Wambua, M.D. (2015): Estimating the prevalence of bovine tuberculosis (btb) using indirect ELISA test in selected counties of Kenya.

Wards, B.; Collins, D. and De Lisle, G. (1995): Detection of Mycobacterium bovis in tissues by polymerase chain reaction Veterinary Microbiology. 43: 227-240.

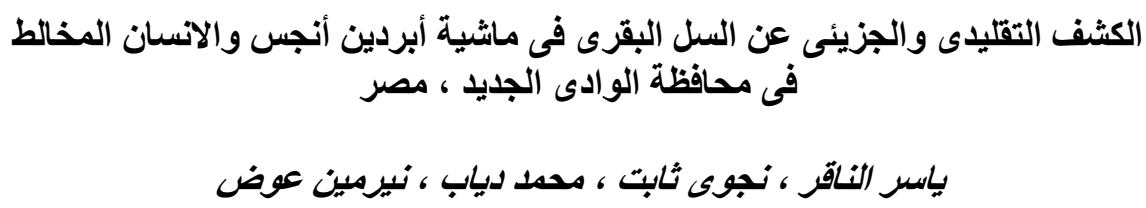

E-mail: yasserelnaker@yahoo.com Assiut University web-site: www.aun.edu.eg

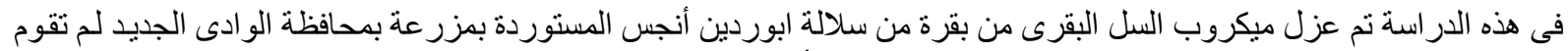

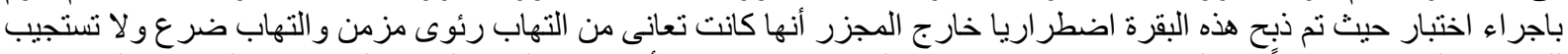

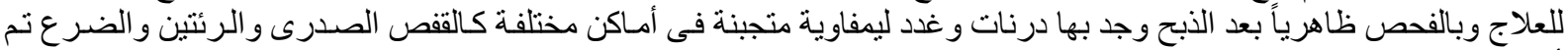

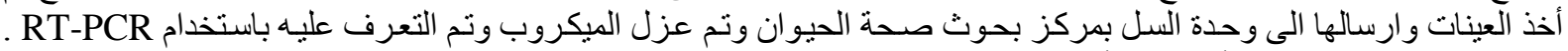

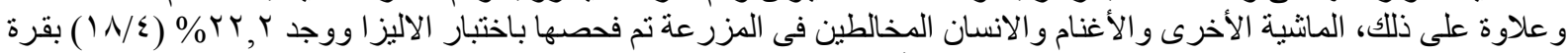

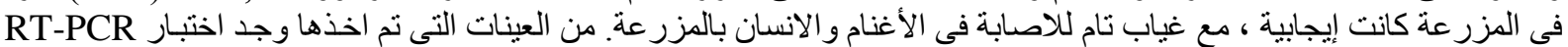

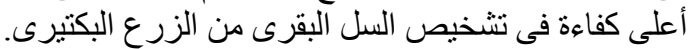

